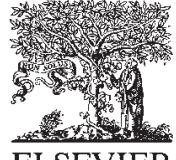

Journal of Development Economics 71 (2003) 289-310

JOURNAL OF

Development ECONOMICS

www.elsevier.com/locate/econbase

\title{
A model of commodity prices after Sir Arthur Lewis
}

\author{
Angus Deaton ${ }^{\mathrm{a}, *}$, Guy Laroque ${ }^{\mathrm{b}}$ \\ ${ }^{a}$ Research Program in Development Studies, Princeton University, 347 Wallace Hall, Princeton, NJ 08544, USA \\ ${ }^{\mathrm{b}}$ Laboratoire de Macroéconomie, INSEE-CREST J360, 15 Boulevard Gabriel Peri, 92245 Malakoff, \\ Paris, France
}

Received 1 January 2001; accepted 1 July 2002

\begin{abstract}
We develop an idea from Arthur Lewis' paper on unlimited supplies of labor to model the longrun behavior of the prices of primary commodity produced by poor countries. Commodity supply is assumed infinitely elastic in the long run, and the rate of growth of supply responds to the excess of the current price over the long-run supply price. Demand is linked to the level of world income and to the price of the commodity, so that price is stationary around its supply price, and commodity supply and world income are cointegrated. The model is fitted to long-run historical data.

(C) 2003 Elsevier Science B.V. All rights reserved.
\end{abstract}

JEL classification: E3; F1; O1

Keywords: Commodity prices; Sir Arthur Lewis; World income; Cointegration

\section{Introduction}

In spite of an extensive literature, the behavior of the prices of primary commodities remains poorly understood. The long-run stagnation, or even secular decline, of the prices of tropical commodities has been attributed to the exercise of market power by Northern manufacturers, and to the supposed low elasticity of demand for primary commodities (Prebisch, 1959; Singer, 1950). The variability of commodity prices has been attributed to supply shocks confronting inelastic demand, and to the behavior of speculators (Deaton and Laroque, 1992). However, none of these accounts are fully satisfactory, either theoretically or empirically. The precise nature of the market power of

\footnotetext{
* Corresponding author.

E-mail addresses: deaton@princeton.edu (A. Deaton), laroque@ensae.fr (G. Laroque).
} 
the North has never been fully explained, nor is it clear in the absence of an account of supply, why it should be that low demand elasticities generate stagnant or declining prices. The theory of short-run dynamics is better understood, but it has a good deal of difficulty accounting for the evidence. In Deaton and Laroque (1992), we showed that a model in which excess supplies were independently and identically distributed over time, the presence of risk neutral speculators could lead to behavior which replicated some of the characteristics of commodity prices, notably long periods of stagnant prices interrupted by sharp upward spikes. However, the speculative model, although capable of introducing some autocorrelation into an otherwise i.i.d. process, appears to be incapable of generating the high degree of serial correlation of most commodity prices. If excess supplies are allowed to be first-order autoregressive, the model can provide a better fit to the data (Deaton and Laroque, 1996). However, and contrary to our expectations before doing the work, we found that, in order to fit the data, the autocorrelation coefficients of excess supply had to be almost as large as the autocorrelation in the prices themselves. The introduction of speculative inventories, although affecting the skewness and kurtosis of the series, does not appear to contribute much to the autocorrelation of prices. We are therefore left without a coherent explanation for the high degree of autocorrelation in commodity prices, just as we have no coherent explanation for the trend.

In this paper, we turn away from inventories as an explanation for the short-run dynamics of prices, and focus instead on the longer-run determinants. In our previous work, our main concern was with the effect of speculative storage on otherwise i.i.d. excess supplies, which were themselves, following much of the previous literature, driven more by supply than demand. Weather-driven quantity shocks are the archetypal driving forces for models of agricultural prices, if only because demand seems an unlikely candidate to explain variability. However, precisely because demand is more highly autocorrelated, it is a good candidate to explain autocorrelation, and this is one of our starting points. On the supply side, we start from the account of Lewis (1954) in his famous paper on growth with unlimited supplies of labor. Lewis was concerned with finding an explanation for the fact that, in spite of technical progress in the industry, the price of West Indian sugar persistently declined relative to the prices of imported manufactured goods. He argued that, as long as there was an infinitely elastic supply of labor at the subsistence wage, world sugar prices could not rise, and might even decline with local technical progress. Lewis' model provides our starting point on the supply side.

We propose a time-series version of the Lewis model in which commodity supply is infinitely elastic in the long run, and in which the rate of growth of supply responds to the excess of the current price over the long-run supply price. Demand is linked to the level of world income and to the price of the commodity. In this simple framework, the commodity price is stationary around its supply price, and commodity supply and world income are cointegrated. Because there are long lags in supply, at least for some commodities, the price process reverts only slowly to its mean, and in the short run is driven by fluctuations in world income, itself a strongly trending process. In this way, the model predicts that in the short run, prices will move with income, which is nonstationary but, unlike income, they will be stationary in the long run. 
That such an account is broadly consistent with some of the evidence is illustrated in Figs. 1 and 2 for the case of sugar, the commodity of most concern to Lewis. Fig. 1 shows, on log scales, world real income in billions of 1980 (purchasing power parity) dollars, together with world production of sugar in hundreds of millions of quintals (see Appendix A for sources). Both series trend strongly upward, with the trend of sugar production somewhat less than that of world income, consistent with a long-run income elasticity somewhat less than unity. By contrast, the world price of sugar, shown as an index in Fig. 2, has not risen relative to the US CPI (a convenient deflator) over the long run. In common with many commodity prices over the long run, the trend is small relative to the variability, so that it is possible to see upward or downward "trends" over prolonged periods. Over the whole period, the price is at least roughly consistent with its being a stationary time-series.

In our previous work, the short-run autocorrelation of commodity prices came from the fact that for speculative arbitrageurs to hold inventories, expected price growth must match interest and holding costs; in the long run, we assumed a stationary excess of supply over demand, with occasional stockouts guaranteeing that price processes are stationary. In the current model by contrast, supply and demand are described separately, and price behavior comes from the action of an integrated (trending) demand process against a supply function that is infinitely elastic in the long run but not the short run. Although we do not attempt to do so, it should be noted that there is nothing in principle that would prevent the incorporation of speculative arbitrage into the Lewis model proposed here.

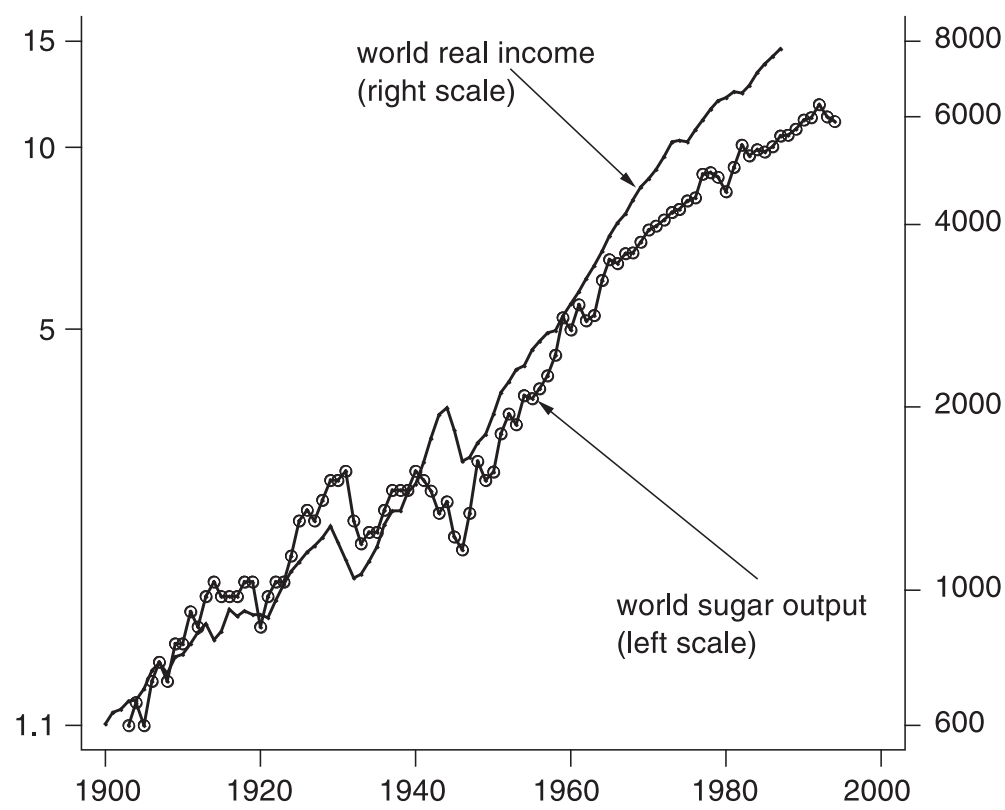

Fig. 1. Sugar production and world real income. 


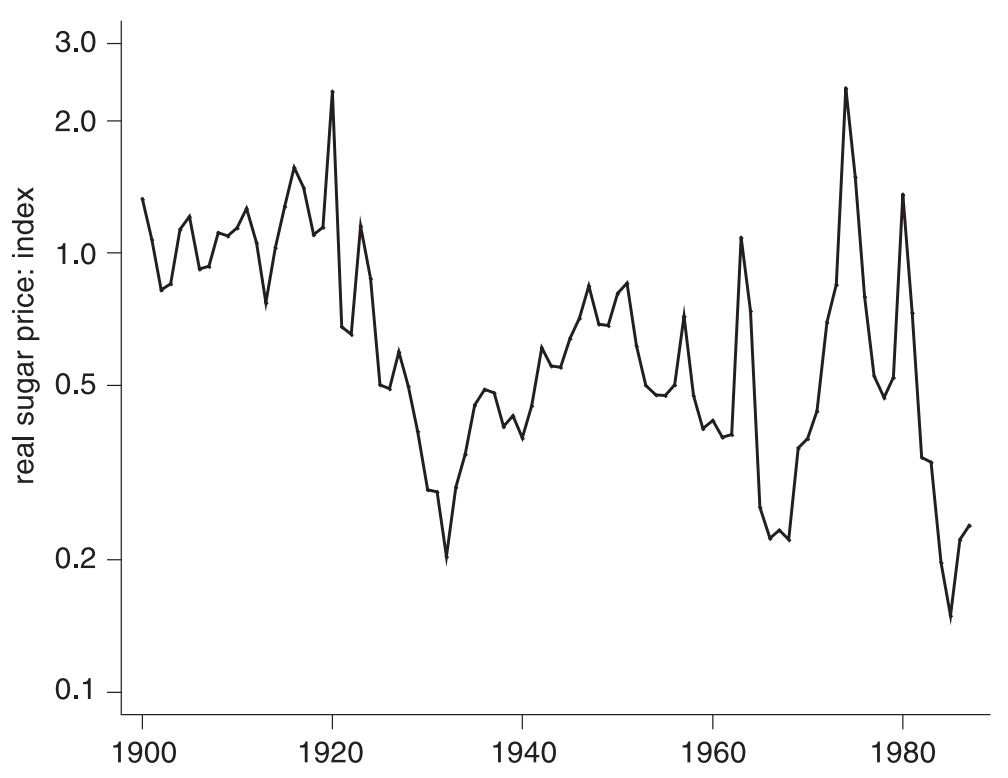

Fig. 2. Sugar prices, deflated by the US consumer price index.

The Lewis argument is addressed to agricultural commodities. For mineral products, first dealt with by Gray (1914) and Hotelling (1931), the owners of the reserves must receive an adequate income for holding their stock of capital. In the long run, therefore, arbitrage guarantees that the discounted price of the resource in situ stays constant, or that the observed rate of growth of the price equals the interest rate. Note that this parallels the short-run behavior of inventories of agricultural commodities. However, in (only apparent) contradiction of Hotelling, the market prices of minerals, like the market prices of agricultural crops, do not exhibit clear trends. In fact, the arbitrage argument applies to the shadow price of resources in the ground, while the observed price series are for the extracted material. Hotelling himself (see also Halvorsen and Smith, 1991) noted that the price in the ground may decline if extraction costs increase when the overall remaining stock is depleted. In a similar vein, if the extraction costs are the main component of the observed price, and if these costs are the wages of subsistence workers employed to do the extraction, the Lewis model is more relevant than the Hotelling story for understanding prices. This will be the case if in situ stocks of the minerals are very large, so that extraction costs dominate rents in commodity prices, and it is that version of events that we follow here. Even if it is true that labor is the main component of costs for both agricultural and mineral products, there are other differences, for example, in the nature of productivity shocks, and we will note and discuss these as we develop and interpret the model.

Section 2 of the paper presents our version of the Lewis model, first in a stripped down form, and then in a form suitable for empirical implementation. Section 3 discusses our data and presents preliminary descriptive analysis in light of the model. Section 4 presents estimates and their interpretation. Section 5 concludes. 


\section{A model of commodity prices}

We start with a simple version of the model which illustrates the main issues, and then state a more formal version that will be used as the basis for the empirical analysis in subsequent sections. Consider the partial equilibrium model for a typical commodity that is traded internationally. Final demand is assumed to be a log-linear (constant elasticity) function of world income (world GDP) and of the world price. The rate of growth of world income is assumed to be a stationary stochastic process, with the (unconditional) mean growth constant over time so that, in time-series language, the logarithm of world income is a nonstationary integrated of order $1, I(1)$, process. Formally,

$$
d_{t}=A y_{t}-B p_{t}+k+\xi_{t}^{d}
$$

where lower case $d_{t}, y_{t}$, and $p_{t}$ are the logarithms of quantity demanded, income, and price, $A, B$, and $k$, are parameters, and $\xi_{t}^{d}$ is a stationary, unobservable, $I(0)$ random variable. We expect that $A>0$, so that demand, exclusive of price movements, is increasing in world income.

The supply process is less standard, and is a simple version of the Lewis model. We write

$$
s_{t}=s_{t-1}+D\left(p_{t}-p^{*}\right)+\xi_{t}^{s}
$$

where $s_{t}$ is the logarithm of supply, and $\xi_{t}^{s}$ is a supply shock, also an unobservable, stationary, $I(0)$ random variable. The price $p^{*}$ is interpreted as the marginal cost of production on marginal land, or the marginal cost of extraction for a mineral. In line with the Lewis assumption of unlimited supplies of labor at the subsistence wage, $p^{*}$ is taken to be constant. Because $D>0$, supply is increased when price is above marginal cost, and vice versa when price is below marginal cost. We assume that the error term $\xi_{t}^{s}$ is stationary and $I(0)$. In particular, we need to permit both permanent (more or less land, a new mine, or a technological shift) and transitory (weather, pests, miner strikes or epidemics) shocks to supply so that, for example, we might have

$$
\xi_{t}^{s}=\eta_{t}+v_{t}-v_{t-1}
$$

where $\eta_{t}$ and $v_{t}$ are the permanent and transitory shocks, respectively. In much of the discussion in the literature, prominence is given to weather shocks for agricultural products, and such shocks would normally be thought of as transitory. For minerals, shocks are perhaps more likely to be permanent. Even so, shocks that affect labor costs or labor productivity could have much the same effect on both types of commodities.

In the absence of inventories, price is determined by equalizing supply and demand, so that

$$
p_{t}=(B+D)^{-1}\left(A y_{t}+k-s_{t-1}+D p^{*}+\xi_{t}^{d}-\xi_{t}^{s}\right)
$$


If Eq. (4) is substituted into the supply process (Eq. (2)), we get the stochastic process for supply:

$$
s_{t}=(B+D)^{-1}\left[B s_{t-1}+A D y_{t}+D k-D B p^{*}+D \xi_{t}^{d}+B \xi_{t}^{s}\right]
$$

or

$$
\Delta s_{t}=(B+D)^{-1}\left[D\left(A y_{t-1}-s_{t-1}\right)+A D \Delta y_{t}+D k-D B p^{*}+D \xi_{t}^{d}+B \xi_{t}^{s}\right]
$$

Eq. (4) can be rewritten to give $s_{t-1}$ as a function of $p_{t}$. Leading the result by one period gives $s_{t}$ in terms of $p_{t+1}$ and the two equations can be inserted into Eq. (5) to eliminate supply and its lag. Lagged one period, we obtain

$$
p_{t}-p^{*}=(B+D)^{-1}\left[B\left(p_{t-1}-p^{*}\right)+A \Delta y_{t}+\Delta \xi_{t}^{d}-\xi_{t}^{s}\right]
$$

These two equations, Eqs. (6) and (7), capture in stripped-down form the central features of our implementation of the Lewis model. In spite of the fact that world income is nonstationary, with possible positive growth, Eq. (7) shows that the commodity price is stationary, fluctuating around its long-run value of $p^{*}+A \mu / D$, where $\mu$ is the mean growth rate of income, $E(\Delta y)$. This long-run value of the price guarantees that, over the long run, supply increases at the same rate as world income so that, as shown in Eq. (6), output of the crop is cointegrated with world income. Of course, the Lewis model only supposes that supply is infinitely elastic in the long run; in the short run, price will respond to fluctuations in demand and supply. However, price has no long-run trend.

The supply and demand disturbances in the structural models (Eqs. (1) and (2)) are typically autocorrelated. To accommodate this, and to develop a model for the empirical implementation whose residuals are innovations, we now introduce an autoregressive formulation.

We start by generalizing the original demand and supply equations to include more realistic responses to prices. Demand is likely to be a function, not only of current income and prices, but also of past and expected future income and prices. Similarly, we would normally think of forward-looking profit maximizing producers as responding to expected future prices. One modeling strategy would be to write down structural supply and demand functions depending, among other things, on expected future variables, and then to proceed as usual for rational expectations models, postulating time-series processes for prices, and solving for their properties. Such a strategy has the potential advantage of yielding restrictions on the lag structure of prices, but only if we are confident about the underlying structure of supply and demand functions. Given that we do not have such information, we adopt a reduced form distributed lag specification while emphasizing that such a model, while not necessarily incorporating all the restrictions from a structural form, encompasses a model of rational, forward-looking behavior.

Our model includes world income in the demand function, but excludes it from the supply function. This is a standard assumption, and is central to a Lewis interpretation. Lewis wanted to know why West Indians remained poor, and the price of sugar low, in 
a world where income and the demand for sugar were steadily increasing. If income were included in the supply equation, there would be no story to tell. More formally, the exclusion of income from the supply equation will allow us to identify its parameters in the last section of the paper, though our reduced form results do not depend on it.

We now write:

$$
\begin{aligned}
& \Delta d_{t}=A(L) y_{t}-B(L) p_{t}+C(L) d_{t-1}+k+\epsilon_{t}^{d} \\
& \Delta s_{t}=D(L)\left(p_{t}-p^{*}\right)+E(L) \Delta s_{t-1}+\epsilon_{t}^{s}
\end{aligned}
$$

where $L$ is the lag operator, $A(L), B(L), C(L), D(L)$, and $E(L)$ are finite polynomials in the lag operator, and we assume that

$$
D(1) \neq 0, \quad C(1) \neq 0, \quad A(1) \neq 0, \quad D(0)+B(0) \neq 0
$$

As before, we assume that $y_{t}$ is $I(1)$ and, in addition, that the error terms $\epsilon_{t}^{d}$ and $\epsilon_{t}^{s}$ are innovations and that enough lags have been introduced to ensure this.

The price can be eliminated from Eqs. (8) and (9) by multiplying the former by $B(L)$, the latter by $D(L)$, and adding, so that, using the notation $q_{t}$ to denote both supply and demand, $q_{t}=s_{t}=d_{t}$, we have

$$
\begin{aligned}
{[D(L)+B(L)] \Delta q_{t}=} & D(L)\left[A(L) y_{t}+C(L) q_{t-1}\right]+B(L) E(L) \Delta q_{t-1}+D(1) k \\
& -B(1) D(1) p^{*}+D(L) \epsilon_{t}^{s}+B(L) \epsilon_{t}^{s}
\end{aligned}
$$

while, for the price,

$$
[D(L)+B(L)] p_{t}=A(L) y_{t}+C(L) q_{t-1}-E(L) \Delta q_{t-1}+k+D(1) p^{*}+\epsilon_{t}^{d}-\epsilon_{t}^{s}
$$

Eq. (12) implies that production is cointegrated with world income. To see this, note first that, since $A(L)$ is finite, $A(1)$ is nonzero, and $y_{t}$ is $I(1), A(L) y_{t}$ on the right-hand side of Eq. (11) is also $I(1)$. Suppose that $q_{t}$ is integrated of order $m$. Then because $C(1) D(1)$ is nonzero, the first term on the right-hand side of Eq. (11), and thus the right-hand side itself, is integrated of order $\max (1, m)$ If $m$ was 2 or larger, the righthand side would be integrated of order $m \geq 2$ while the left-hand side would be integrated of order $m-1$, which is a contradiction. Similarly, if $m \leq 0$, the right-hand side is integrated of order 1 , and the left-hand side integrated of order less than -1 , again a contradiction. In consequence, $m=1$, and since the right-hand side is $I(0)$, so is $A(L) y_{t}+C(L) q_{t-1}$, so that $q_{t}$ and $y_{t}$ are cointegrated. Consequently, by Eq. (12), the price $p_{t}$ is stationary.

In order to estimate the model, it is convenient to rewrite the equations to put them into vector error-correction model (VECM) form. Start from the first term on the right-hand side of Eq. (11), and rewrite as

$$
A(L) y_{t}+C(L) q_{t-1}=\left[A(1) y_{t-1}+C(1) q_{t-1}\right]+\tilde{A}(L) \Delta y_{t}+\tilde{C}(L) \Delta q_{t-1}
$$


so that all three terms on the right-hand side are stationary. The first term, in square brackets, is referred to as the "cointegration term". If Eq. (13) is substituted into Eq. (8), and Eqs. (8) and (9) are solved for $p_{t}$ and $\Delta q_{t}$, we get two equations with current $\Delta q_{t}$ and $p_{t}$ on the left-hand side, while the right-hand side has the cointegration term, $\Delta q_{t-1}$ and its lags, $p_{t-1}$ and its lags, and $\Delta y_{t}$ and its lags. If we are prepared to maintain that $\Delta y_{t}$ is strictly exogenous, this form would be sufficient, but instead, we complete the system by adding an equation for the change in income

$$
\Delta y_{t}=a_{0}+a_{1}\left[A(1) y_{t-1}+C(1) q_{t-1}\right]+F(L) \Delta y_{t-1}+G(L) \Delta q_{t-1}+H(L) p_{t-1}+\epsilon_{t}^{y}
$$

where $\epsilon_{t}^{y}$ is an innovation. With this final substitution, we obtain a three equation system in VECM form,

$$
\begin{aligned}
& \Delta q_{t}=b_{q 0}+b_{q 1}\left(\theta y_{t-1}-q_{t-1}\right)+B_{q q}(L) \Delta q_{t-1}+B_{q p}(L) p_{t-1}+B_{q y}(L) \Delta y_{t-1}+\eta_{t}^{q} \\
& p_{t}=b_{p 0}+b_{p 1}\left(\theta y_{t-1}-q_{t-1}\right)+B_{p q}(L) \Delta q_{t-1}+B_{p p}(L) p_{t-1}+B_{p y}(L) \Delta y_{t-1}+\eta_{t}^{p}
\end{aligned}
$$

$$
\Delta y_{t}=b_{y 0}+b_{y 1}\left(\theta y_{t-1}-q_{t-1}\right)+B_{y q}(L) \Delta q_{t-1}+B_{y p}(L) p_{t-1}+B_{y y}(L) \Delta y_{t-1}+\eta_{t}^{y}
$$

These three equations will be estimated in Section 4. Because the supply Eq. (9) excludes world income or its rate of growth, and because the demand Eq. (8) excludes nothing (see also Eqs. (1) and (2)), only the parameters of the supply equation are identified, together with the cointegration parameter $\theta$, which is the long-run income elasticity of demand for the commodity. The algebra for the identification is tedious, but does not differ substantively from the elementary treatment of identification in supply and demand systems. Because the system is overidentified, there are restrictions that must hold on Eqs. (15)-(17) to make them consistent with the structure. The ratio of the coefficient on the cointegration term in the quantity equation, $b_{q 1}$ to the coefficient on the cointegration term in the price equation, $b_{p 1}$ must be the same as the ratios of the polynomials on $\Delta y_{t-1}$, so that

$$
\frac{b_{q 1}}{b_{p 1}}=\frac{B_{q y}(n)}{B_{p y}(n)}
$$

for all $n$ up to the maximum lag on $\Delta y_{t-1}$. Provided the restrictions are satisfied, the ratio is the short-run elasticity of supply to price, $D(0)$. The original supply equation is obtained 
by subtracting $D(0)$ times the price Eq. (16) from the quantity growth Eq. (15); this identifies all the parameters of Eq. (9).

Conditional on the validity of the cointegration of $y_{t}$ and $q_{t}$ and of the stationarity of $p_{t}$, the system can be consistently and efficiently estimated by standard FIML applied to the three equations, with or without the restrictions, with the FIML variance covariance matrix used to construct $t$-tests, $F$-tests, and likelihood ratio tests (see Ahn and Reinsel, 1990; Watson, 1994).

\section{Data and preliminary analysis}

In our previous work on commodity prices, we worked entirely with price data, mostly with relatively long historical data for most of the 20th century. There are great advantages to the price data. They are high quality data, available over long periods of time, and in recent years, at high frequency, and they cover a large number of commodities. Nevertheless, a fuller understanding of the processes involved would seem to require an examination of quantities as well as covariates such as income, and given our previous lack of success in providing a coherent account of price behavior, it is necessary to take the broader view. Unfortunately, long-run production and income data are a great deal harder to come by than price information, and a good deal less accurate. In particular, there is an almost complete absence of adequate long-run data on inventories of commodities, so that our neglect of this aspect of the problem is forced by data considerations if for no other reason. In Appendix A, we provide brief details of the construction and sources for the production and income data that we use; since this work is not easily reproduced, we also present the data. They include a series for real world income, which runs from 1900 to 1987 , and this is matched to world production data for cocoa (from 1901), for coffee (from 1930), for copper, for rice (from 1904), for sugar (from 1903), and for tin (from 1901). Average annual prices for all of these goods are available from the same World Bank sources that were used in our earlier work, and these were deflated, as before, by the US consumer price index.

We begin by presenting some descriptive statistics in Table 1 . Column 2 shows that the deflated prices all had negative growth rates over most of the 20th century; this is the well-researched decline in the terms of trade for primary commodities. However, it should be noted from the next two columns that none of these trends are significantly different from zero; even using the (smaller) standard error that allows for possible serial correlation, in only one case, rice, is the estimated rate of decline larger than its standard errors, and then only marginally so. The lack of significant trends is consistent with the stationarity of the price predicted by the theory, though it is far from ruling out nonstationary alternatives. Of course, the standard errors are large because the prices are so variable, so that the findings in the top half of the table might be summarized by saying that prices exhibit some downward trend, but the trend is small relative to variability.

In contrast to prices, production levels tend to exhibit significant positive trends. All the coefficients are positive, and except for coffee and tin, which each rose at less than $1 \%$ a 
Table 1

Summary data on prices, production, and income

\begin{tabular}{|c|c|c|c|c|}
\hline Commodity & Dates covered & $\begin{array}{l}\text { Mean rate } \\
\text { of growth }\end{array}$ & $\begin{array}{l}\text { Standard } \\
\text { error }\end{array}$ & $\begin{array}{l}\text { Corrected } \\
\text { standard error }\end{array}$ \\
\hline \multicolumn{5}{|l|}{ Prices } \\
\hline Cocoa & $1901-1987$ & -0.0084 & 0.029 & 0.023 \\
\hline Coffee & $1901-1987$ & -0.0004 & 0.026 & 0.020 \\
\hline Copper & $1901-1987$ & -0.0111 & 0.019 & 0.013 \\
\hline Rice & $1901-1987$ & -0.0168 & 0.021 & 0.015 \\
\hline Rubber & $1948-1991$ & -0.0254 & 0.054 & 0.024 \\
\hline Sugar & $1901-1987$ & -0.0197 & 0.040 & 0.026 \\
\hline Tin & $1901-1987$ & -0.0003 & 0.021 & 0.015 \\
\hline \multicolumn{5}{|l|}{ Production } \\
\hline Cocoa & $1902-1988$ & 0.0339 & 0.012 & 0.008 \\
\hline Coffee & $1931-1990$ & 0.0088 & 0.026 & 0.014 \\
\hline Copper & $1901-1990$ & 0.0333 & 0.014 & 0.008 \\
\hline Rice & $1905-1987$ & 0.0223 & 0.008 & 0.006 \\
\hline Rubber & $1947-1990$ & 0.0407 & 0.011 & 0.013 \\
\hline Sugar & $1904-1994$ & 0.0253 & 0.008 & 0.006 \\
\hline Tin & $1902-1987$ & 0.0048 & 0.016 & 0.009 \\
\hline \multicolumn{5}{|c|}{ World income } \\
\hline Income & $1901-87$ & 0.0294 & 0.004 & 0.004 \\
\hline
\end{tabular}

The dates covered exclude the first observation lost to differencing. The mean rate of growth is the average of the change in logarithms over the period shown. The standard errors are standard errors of the mean rate of growth, in the first column ignoring serial correlation, and in the second, using the Newey-West procedure with 10 (annual) lags.

year, all are significantly different from zero. World income grew at $2.94 \%$ a year from 1900 to 1987 , so that Table 1 is not inconsistent with the underlying Lewis view that, in the long run, demand drives supply with no effect on price.

Table 2 reports the results of using unit root tests to investigate the stationarity issues further. We show the results of regressions of the rates of growth of prices, production, and world income on the lagged logarithm of the level, and five lagged values of growth rates. For a series that is $I(1)$, the coefficient $\rho-1$ on the lagged logarithm should be zero, and the comparison of the standard $t$-value against appropriate critical values can be used to test the null of $I(1)$. If the series is integrated with nonzero drift, the $t$-statistic can be compared against the usual distribution; if there is no drift, the critical values are nonstandard, and are given, for example, in Hamilton (1994). It is also interesting to test the joint hypothesis that the drift is zero and the coefficient on the lagged logarithm is zero, so that the series is $I(1)$ without drift. The $F$-statistic in the table is calculated in the usual way, and gives a test that is valid under the null if compared against special critical values (see Hamilton, 1994 and the notes to the table).

The major practical problem with all of these tests is lack of power; it is typically difficult to reject the null, and failure to do so must not be taken as a confirmation. For example, the top part of the table shows only two rejections, for cocoa and coffee, both 
Table 2

Time-series characteristics of prices, production, and world income

\begin{tabular}{|c|c|c|c|c|c|c|c|c|c|}
\hline Commodity & Constant & S.E. & $\rho-1$ & S.E. & $t$ & $F$ & Test 1 & Test 2 & Test 3 \\
\hline \multicolumn{10}{|l|}{ Prices } \\
\hline Cocoa & -0.228 & $(0.109)$ & -0.228 & $(0.058)$ & -2.08 & 2.21 & $\times$ & 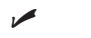 & 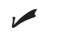 \\
\hline Coffee & -0.287 & $(0.123)$ & -0.185 & $(0.077)$ & -2.41 & 2.89 & $\times$ & 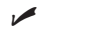 & $\swarrow$ \\
\hline Copper & -0.101 & $(0.049)$ & -0.110 & $(0.059)$ & -1.86 & 2.10 & $\swarrow$ & 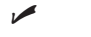 & $\swarrow$ \\
\hline Rice & -0.061 & $(0.042)$ & -0.077 & $(0.072)$ & -1.06 & 1.20 & $\swarrow$ & $\swarrow$ & $\swarrow$ \\
\hline Rubber & 0.460 & $(0.460)$ & -0.162 & $(0.138)$ & -1.18 & 2.02 & 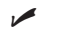 & $\swarrow$ & $\swarrow$ \\
\hline Sugar & -0.113 & $(0.060)$ & -0.166 & $(0.093)$ & -1.79 & 1.94 & $\swarrow$ & 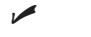 & $\swarrow$ \\
\hline Tin & 0.179 & $(0.102)$ & -0.116 & $(0.063)$ & -1.84 & 1.72 & $\swarrow$ & 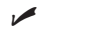 & 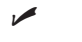 \\
\hline \multicolumn{10}{|l|}{ Production } \\
\hline Cocoa & 0.327 & $(0.133)$ & -0.042 & $(0.019)$ & -2.14 & 6.09 & $x$ & 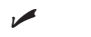 & $\times$ \\
\hline Coffee & 0.803 & $(0.878)$ & -0.074 & $(0.083)$ & -0.89 & 0.67 & 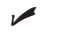 & $\swarrow$ & $\swarrow$ \\
\hline Copper & 0.161 & $(0.152)$ & -0.014 & $(0.019)$ & -0.72 & 4.68 & $\swarrow$ & $\swarrow$ & $\swarrow$ \\
\hline Rice & 0.202 & $(0.366)$ & -0.008 & $(0.017)$ & -0.45 & 5.51 & $\swarrow$ & $\swarrow$ & $\times$ \\
\hline Rubber & -0.073 & $(0.186)$ & 0.014 & $(0.186)$ & 0.60 & 5.03 & $\swarrow$ & $\swarrow$ & $\times$ \\
\hline Sugar & 0.035 & $(0.020)$ & -0.005 & $(0.014)$ & -0.34 & 3.47 & $\swarrow$ & $\swarrow$ & $\swarrow$ \\
\hline Tin & 2.683 & $(0.958)$ & -0.225 & $(0.081)$ & -2.79 & 4.02 & $\times$ & $\mathscr{}$ & 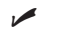 \\
\hline \multicolumn{10}{|l|}{ World income } \\
\hline World income & -0.084 & $(0.108)$ & 0.006 & $(0.006)$ & 1.05 & 9.03 & $\swarrow$ & $\swarrow$ & $\times$ \\
\hline
\end{tabular}

For each row of the table, a regression is run with the dependent variable the change in logarithm, and the independent variables a constant, the lagged logarithm, and five lagged changes of logarithms. The first five columns shown are the estimates of the constant term, its standard error, the coefficient on the lagged logarithm, its standard error, and its $t$-value. The sixth column shows an $F$-test for the joint hypothesis that both the constant term and the coefficient on the lagged logarithm are zero. The three test columns report acceptance $(\mathscr{})$ or rejection $(\times)$ at the $5 \%$ level of (1) the hypothesis that the coefficient on the lagged logarithm is zero, under the assumption that the constant term is non-zero, so that standard inference is applied to the $t$-ratio; (2) the same hypothesis, but under the assumption that the constant term is zero, so that this augmented Dickey Fuller test, using the same $t$-statistics as (1), is tested using nonstandard distributions, here Table B.6 (Case 2) in Hamilton (1994); (3) the hypothesis that both the constant and the coefficient on the lag are zero using the $F$-test in column 6 and the distributions given in Table B.7 (Case 2) in Hamilton which are calculated under the null that the restrictions hold.

in the first column, where we test the null of $I(1)$ under the hypothesis that the series is I(1) with nonzero drift. Because the coefficients on the lagged price levels are negative, the departure is in the direction of stationarity, as suggested by the model. However, for the other commodities, and for cocoa and coffee under the alternative specification of $I(1)$ without drift, it is impossible to reject the null of integration, nor can we reject the hypothesis that the data are indeed $I(1)$ without drift. Clearly, we cannot use these tests to reject the null that prices are integrated, which would contradict the Lewis model.

Nevertheless, it is clear that these results cannot be taken too seriously. Indeed, one of the most obvious characteristics of commodity price series is the combination of high autocorrelations at high frequency, coupled with a lack of long-run trend. In Deaton and Laroque (1992), we calculated variance-ratio or persistence statistics, which provided evidence in favor of stationarity. Standard unit root tests, such as those used here, work 
with a small number of lags, and are liable to miss the slow mean reversion that is captured by the variance-ratio statistics. Note that the results in the top half of the table are also consistent with stationary autoregressive models for prices. For example, the standard errors on the lagged coefficient are such that for no commodity can we reject the hypothesis that the coefficient on lagged price is 0.8 , or -0.2 for $\rho-1$. The unit root tests are essentially uninformative about the stationarity or otherwise of commodity prices.

The unit root tests for production and for world income are presented in the bottom half of the table. While they suffer from the same sort of problems as the price tests, there are much larger and more obvious drifts in the production (and income) series, and the joint tests for integration without drift reject in a number of cases. Of more concern are the rejections of integration for cocoa and tin; while the rejection is marginal for the former, the production of tin appears to be better represented by a stationary than a nonstationary process.

Table 3 shows cointegration tests for production and demand. These follow the original suggestion of Engle and Granger (1987) of first calculating an OLS regression of $\log$ production on log income, and then analyzing the residuals. In this case, the coefficient in the first regression has the interpretation of the long-run income elasticity of demand. These are presented in the first column. Apart from tin, and more surprisingly, coffee, the elasticities are not particularly low. The estimated residuals are used in the same type of regression described above, regressing the change on the lagged level and on five lagged changes. The $t$-statistic on the lagged level is used, again with tailored critical values, to test the null of no cointegration. If there is no cointegration, the first-stage regression is spurious, the residuals should contain a unit root, so the test against unity is a test for $I(1)$; the different critical values from those in Table 2 reflect the fact that the residuals involve an estimated parameter. Apart from tin, and almost for rice, we cannot reject the null of no cointegration. While the absence of cointegration would be a problem for the Lewis model, the results likely owe as much to

Table 3

Cointegration tests for the $\log$ of production and the $\log$ of world income

\begin{tabular}{lllll}
\hline Commodity & $\begin{array}{l}\text { Long-run } \\
\text { elasticity }\end{array}$ & $\begin{array}{l}\text { Coefficient } \\
\text { on } \hat{u}_{t-1}\end{array}$ & $\begin{array}{l}\text { Standard } \\
\text { error }\end{array}$ & $\begin{array}{l}t \text {-value } \\
\text { for } 1\end{array}$ \\
\hline Cocoa & 0.89 & 0.848 & 0.055 & -2.75 \\
Coffee & 0.39 & 0.637 & 0.142 & -2.55 \\
Copper & 1.08 & 0.605 & 0.131 & -3.02 \\
Rice & 0.70 & 0.702 & 0.091 & -3.28 \\
Rubber & 0.78 & 0.648 & 0.144 & -2.45 \\
Sugar & 0.84 & 0.765 & 0.086 & -2.72 \\
Tin & 0.22 & 0.431 & 0.135 & -4.13 \\
\hline
\end{tabular}

The long-run elasticity is the OLS coefficient on the logarithm of world income in the cointegrating regression of $\log$ production on log output. The residuals from this regression are then regressed on their own lag and on five lagged first differences. The coefficient on the lag is shown, together with its estimated standard error, and the conventional $t$-value for the hypothesis that the coefficient is unity. Critical values for this $t$-value statistic are given in Hamilton, Table B8, Case 2. Only the value for tin exceeds its 5\% critical in Hamilton's table. 
lack of power as to any genuine failure of cointegration; in particular note that all the estimated coefficients on $\hat{u}_{t-1}$ are less than 0.85 , and that five out of the seven are 0.7 or less.

The predictions of the Lewis model that prices are stationary and that quantities and world demand are cointegrated are not obviously confirmed by these simple tests. Prices are slow to revert to their long-run means, as are the ratios of commodity production to world income. However, it is well known that such slow reversion is poorly captured by tests that rely on a few low-order autocorrelations, and we take the view that the descriptive tests are essentially neutral as far as the validity of the model is concerned.

\section{Results of estimating the model}

Tables 4 and 5 show the reduced form and structural parameter estimates for each of the goods, cocoa, coffee, and copper in Table 4, and rice, sugar, and tin in Table 5. For each commodity, the top three panels present the reduced form parameters, for the price equation, Eq. (16), for the production equation, Eq. (15), and for the world income equation, Eq. (17). The row labeled "cointegrating" is the parameter estimate on the cointegration term $\theta y_{t-1}-q_{t-1}$, the difference between (logarithmic) demand and supply. Other rows correspond to the coefficients on lags of price, production change, and income change. The fourth panel shows the estimate of the cointegrating constant $\theta$; this is the estimate of the long-run elasticity of demand, already estimated by the two-step Engle-Granger procedure in Table 3. The final panel shows the structural parameters for the supply equation - the demand equation is not identified except for the long-run elasticity from the cointegrating relationship.

Except for rice, for which we could only obtain sensible results with a single lag, we show results with two lags of prices, production and world income growth. We tested the overidentification restrictions (Eq. (18)) using likelihood ratio tests from FIML estimation with and without the restrictions. The restrictions easily passed the test for all of the commodities, and we present only the restricted estimates, which allow us to recover unique estimates for the structural parameters.

The cointegrating parameters provide elasticities of demand that are not very different from those shown in Table 3, and which range from 1.03 for copper and 0.90 to cocoa, to 0.48 for coffee and 0.15 for tin. All of these are quite precisely estimated, with standard errors between 0.04 and 0.08 .

The estimated coefficients of the cointegrating term in the production and price equations are all positive, and for each good, at least one of the coefficients is significantly different from zero. Conditional on lagged prices, production, and world income, an imbalance between lagged demand and lagged supply leads to an increase in price, or output, or both. Although the demand equation is not identified, the model predicts what we see, that these reduced form coefficients be positive, when the cointegration term does not enter the world income equation and the coefficients $B(0)$ and $D(0)$ are both positive. To see this, note first that from the world income estimates in the third panel, we see that in no case are there significant effects of the cointegrating term, lagged quantity changes, or 
Table 4

Reduced form and structural estimates of cocoa, coffee, and copper

\begin{tabular}{|c|c|c|c|c|c|c|}
\hline & \multicolumn{2}{|l|}{ Cocoa } & \multicolumn{2}{|l|}{ Coffee } & \multicolumn{2}{|l|}{ Copper } \\
\hline & Coefficient & S.E. & Coefficient & S.E. & Coefficient & S.E. \\
\hline \multicolumn{7}{|l|}{ Price } \\
\hline Constant & -4.35 & (1.93) & 0.13 & $(0.44)$ & -4.44 & $(1.55)$ \\
\hline Cointegrating & 0.36 & $(0.16)$ & 0.25 & $(0.13)$ & 0.37 & $(0.13)$ \\
\hline$p_{t-1}$ & 0.94 & $(0.12)$ & 0.80 & $(0.14)$ & 1.10 & $(0.12)$ \\
\hline$p_{t-2}$ & -0.22 & $(0.12)$ & 0.03 & $(0.14)$ & -0.23 & $(0.12)$ \\
\hline$\Delta q_{t-1}$ & 0.21 & $(0.30)$ & 0.15 & $(0.20)$ & -0.07 & $(0.16)$ \\
\hline$\Delta q_{t-2}$ & 0.08 & $(0.27)$ & 0.08 & $(0.18)$ & 0.09 & $(0.15)$ \\
\hline$\Delta y_{t-1}$ & -0.35 & $(0.53)$ & 0.08 & $(0.45)$ & 0.36 & $(0.38)$ \\
\hline$\Delta y_{t-2}$ & -0.76 & $(0.57)$ & -1.33 & $(0.66)$ & -0.19 & $(0.35)$ \\
\hline$R^{2} /$ no. of observations & 0.79 & 84 & 0.78 & 45 & 0.81 & 85 \\
\hline \multicolumn{7}{|l|}{ Production } \\
\hline Constant & -1.05 & $(0.70)$ & 0.55 & $(0.39)$ & -5.43 & $(1.29)$ \\
\hline Cointegrating & 0.11 & $(0.06)$ & 0.24 & $(0.09)$ & 0.46 & $(0.10)$ \\
\hline$p_{t-1}$ & -0.05 & $(0.04)$ & -0.36 & $(0.08)$ & 0.16 & $(0.10)$ \\
\hline$p_{t-2}$ & 0.05 & $(0.04)$ & 0.46 & $(0.08)$ & -0.21 & $(0.09)$ \\
\hline$\Delta q_{t-1}$ & -0.46 & $(0.11)$ & -0.59 & $(0.12)$ & 0.09 & $(0.13)$ \\
\hline$\Delta q_{t-2}$ & -0.22 & $(0.10)$ & -0.13 & $(0.11)$ & 0.17 & $(0.12)$ \\
\hline$\Delta y_{t-1}$ & 0.10 & $(0.16)$ & 0.07 & $(0.43)$ & 0.45 & $(0.46)$ \\
\hline$\Delta y_{t-2}$ & -0.22 & $(0.18)$ & -1.26 & $(0.45)$ & -0.23 & $(0.44)$ \\
\hline$R^{2}$ & 0.26 & & 0.65 & & 0.29 & \\
\hline \multicolumn{7}{|l|}{ World income } \\
\hline Constant & 0.57 & $(0.29)$ & -0.04 & $(0.10)$ & -0.39 & $(0.35)$ \\
\hline Cointegrating & -0.05 & $(0.03)$ & -0.06 & $(0.02)$ & 0.03 & $(0.03)$ \\
\hline$p_{t-1}$ & 0.02 & $(0.02)$ & 0.02 & $(0.01)$ & -0.04 & $(0.03)$ \\
\hline$p_{t-2}$ & -0.00 & $(0.02)$ & -0.00 & $(0.01)$ & 0.03 & $(0.03)$ \\
\hline$\Delta q_{t-1}$ & 0.02 & $(0.04)$ & -0.07 & $(0.03)$ & 0.03 & $(0.04)$ \\
\hline$\Delta q_{t-2}$ & 0.04 & $(0.04)$ & -0.04 & $(0.02)$ & 0.02 & $(0.04)$ \\
\hline$\Delta y_{t-1}$ & 0.43 & $(0.11)$ & 0.51 & $(0.11)$ & 0.48 & $(0.13)$ \\
\hline$\Delta y_{t-2}$ & -0.12 & $(0.11)$ & -0.27 & $(0.11)$ & -0.16 & $(0.13)$ \\
\hline$R^{2}$ & 0.24 & & 0.39 & & 0.21 & \\
\hline \multicolumn{7}{|l|}{ Cointegration } \\
\hline$\Delta y_{t-1}$ & 0.90 & $(0.05)$ & 0.48 & $(0.08)$ & 1.03 & $(0.04)$ \\
\hline$D_{0}$ & 0.29 & $(0.23)$ & 0.95 & $(0.49)$ & 1.25 & $(0.37)$ \\
\hline$D_{1}$ & -0.32 & $(0.24)$ & -1.01 & $(0.47)$ & -1.22 & $(0.44)$ \\
\hline$D_{2}$ & 0.11 & $(0.07)$ & 0.43 & $(0.15)$ & 0.08 & $(0.16)$ \\
\hline Total & 0.08 & $(0.04)$ & 0.27 & $(0.10)$ & 0.12 & $(0.07)$ \\
\hline$E_{0}$ & -0.53 & $(0.16)$ & -0.73 & $(0.20)$ & 0.18 & $(0.18)$ \\
\hline$E_{1}$ & -0.24 & $(0.15)$ & -0.21 & $(0.20)$ & 0.06 & $(0.14)$ \\
\hline Total & -0.77 & $(0.33)$ & -0.94 & $(0.59)$ & 0.24 & $(0.50)$ \\
\hline
\end{tabular}

lagged prices, an absence that can be formally confirmed by likelihood ratio tests. Suppose then that all of these coefficients are zero. Then use Eq. (17) to substitute for $y_{t}=\Delta y_{t}+y_{t-1}$ in Eqs. (11) and (12) which yields, after some manipulation, Eqs. (15) 
Table 5

Reduced form and structural estimates of rice, sugar, and tin

\begin{tabular}{|c|c|c|c|c|c|c|}
\hline & \multicolumn{2}{|l|}{ Rice } & \multicolumn{2}{|l|}{ Sugar } & \multicolumn{2}{|l|}{ Tin } \\
\hline & Coefficient & S.E. & Coefficient & S.E. & Coefficient & S.E. \\
\hline \multicolumn{7}{|l|}{ Price } \\
\hline Constant & 5.66 & $(1.77)$ & -6.05 & $(4.83)$ & 0.75 & (1.03) \\
\hline Cointegrating & 0.55 & $(0.19)$ & 0.42 & $(0.34)$ & 0.11 & $(0.11)$ \\
\hline$p_{t-1}$ & 0.76 & $(0.07)$ & 0.84 & $(0.12)$ & 1.17 & $(0.11)$ \\
\hline$p_{t-2}$ & - & - & 0.11 & $(0.12)$ & -0.32 & $(0.11)$ \\
\hline$\Delta q_{t-1}$ & 0.37 & $(0.29)$ & -0.05 & $(0.59)$ & -0.13 & $(0.14)$ \\
\hline$\Delta q_{t-2}$ & - & - & 0.59 & $(0.54)$ & 0.01 & $(0.14)$ \\
\hline$\Delta y_{t-1}$ & 0.38 & $(0.50)$ & 0.66 & $(0.65)$ & 0.10 & $(0.16)$ \\
\hline$\Delta y_{t-2}$ & - & & -0.44 & $(0.53)$ & -0.11 & $(0.17)$ \\
\hline$R^{2} /$ no. of observations & 0.79 & 82 & 0.64 & 82 & 0.80 & 84 \\
\hline \multicolumn{7}{|l|}{ Production } \\
\hline Constant & 0.65 & $(0.69)$ & -2.13 & $(1.03)$ & 3.38 & $(0.89)$ \\
\hline Cointegrating & 0.06 & $(0.07)$ & 0.16 & $(0.07)$ & 0.37 & $(0.09)$ \\
\hline$p_{t-1}$ & 0.01 & $(0.03)$ & 0.02 & $(0.02)$ & 0.15 & $(0.09)$ \\
\hline$p_{t-2}$ & - & - & 0.00 & $(0.02)$ & -0.09 & $(0.09)$ \\
\hline$\Delta q_{t-1}$ & -0.28 & $(0.11)$ & -0.07 & $(0.12)$ & 0.22 & $(0.11)$ \\
\hline$\Delta q_{t-2}$ & - & - & -0.07 & $(0.11)$ & 0.09 & $(0.11)$ \\
\hline$\Delta y_{t-1}$ & 0.04 & $(0.07)$ & 0.25 & $(0.17)$ & 0.34 & $(0.43)$ \\
\hline$\Delta y_{t-2}$ & - & & -0.16 & $(0.17)$ & -0.38 & $(0.41)$ \\
\hline$R^{2}$ & 0.13 & & 0.17 & & 0.27 & \\
\hline \multicolumn{7}{|l|}{ World income } \\
\hline Constant & -0.32 & $(0.35)$ & 0.34 & $(0.57)$ & 0.04 & $(0.23)$ \\
\hline Cointegrating & -0.03 & $(0.03)$ & -0.02 & $(0.04)$ & 0.00 & $(0.03)$ \\
\hline$p_{t-1}$ & 0.00 & $(0.01)$ & -0.00 & $(0.01)$ & 0.01 & $(0.02)$ \\
\hline$p_{t-2}$ & - & - & 0.00 & $(0.01)$ & -0.00 & $(0.02)$ \\
\hline$\Delta q_{t-1}$ & -0.05 & $(0.06)$ & -0.05 & $(0.07)$ & 0.01 & $(0.03)$ \\
\hline$\Delta q_{t-2}$ & - & - & 0.03 & $(0.06)$ & 0.04 & $(0.03)$ \\
\hline$\Delta y_{t-1}$ & 0.40 & $(0.10)$ & 0.48 & $(0.11)$ & 0.42 & $(0.12)$ \\
\hline$\Delta y_{t-2}$ & - & - & -0.17 & $(0.11)$ & -0.14 & $(0.11)$ \\
\hline$R^{2}$ & 0.18 & & 0.20 & & 0.20 & \\
\hline \multicolumn{7}{|l|}{ Cointegration } \\
\hline$\Delta y_{t-1}$ & 0.56 & $(0.06)$ & 0.79 & $(0.05)$ & 0.15 & $(0.07)$ \\
\hline$D_{0}$ & 0.11 & $(0.12)$ & 0.37 & $(0.37)$ & 3.37 & (3.46) \\
\hline$D_{1}$ & -0.07 & $(0.11)$ & -0.29 & $(0.33)$ & -3.80 & (4.14) \\
\hline$D_{2}$ & - & - & 0.04 & $(0.07)$ & 0.98 & (1.26) \\
\hline Total & 0.04 & $(0.03)$ & 0.12 & $(0.09)$ & 0.54 & $(0.58)$ \\
\hline$E_{0}$ & -0.32 & $(0.11)$ & -0.05 & $(0.28)$ & 0.65 & $(0.73)$ \\
\hline$E_{1}$ & - & - & -0.29 & $(0.30)$ & 0.05 & $(0.46)$ \\
\hline Total & -0.32 & $(0.11)$ & -0.34 & $(0.48)$ & 0.70 & $(4.24)$ \\
\hline
\end{tabular}

and (16). This calculation shows that $b_{q 1}$ and $b_{p 1}$ are equal to $D(0) /(D(0)+B(0))$ and $1 /$ $(D(0)+B(0))$, respectively. Although $B(0)$ is not identified, both terms should be positive, which is what we see. 
The lagged values of the growth of world income are generally insignificantly different from zero in the reduced form estimates, the only exception being $\Delta y_{t-2}$ in the copper equation. These weak results are worth noting because the acceptance of the overidentification test depends on them. Although we can accept the overidentification that comes from exclusion of world demand from the supply Eq. (2), world demand plays such a limited role beyond its effects in the cointegrating term that the test is quite unimpressive.

World income is well modeled as an AR(1) in first-differences with an autocorrelation coefficient of 0.4 . Lagged prices, lagged production growth, and shortfall of supply over demand have essentially no detectable effects on the rate of growth of world income, something that can be confirmed by a series of Granger noncausality tests, all of which are easily passed. This result is perhaps not surprising given the limited importance of these commodity markets in the world economy.

The response of supply to price is detailed in the bottom panel which shows the structural estimates of the supply equation. A pattern that is repeated across all of the commodities is one in which there is a positive instantaneous effect of price on production, followed by a negative effect at one lag. At the third lag, the response is in all case positive (except for rice where it is constrained to be zero) and the sum of the responses is (again in all cases) positive. However, once again, although the signs are right, the results are not always significantly different from zero, and we find a significantly positive long-run price response of the growth of supply for only cocoa and coffee. The offsetting effects in the first and second period can perhaps be attributed to the existence of a short supply response in which the level of supply responds to the level of prices, so that the growth of supply is linked to the growth of prices. This short-run response might be linked to inventory behavior. Since it is extremely difficult to obtain accurate data on inventories, the production series that we use are almost certainly in part consumption series. If so, and if price increases elicits a short-run response out of inventories, there will appear to be a short-run response of "production" to price.

The Lewis model postulates that long-run supply is infinitely elastic, so that the elasticity we are interested in here is by how much the rate of growth of production responds to a difference between the current price and the long-run equilibrium price. These elasticities are computed by dividing the sum of the supply coefficients (shown as "total") in the last panel by one plus the sum of the coefficients on the lagged $\Delta y$ terms. Apart from tin, where all the supply parameters are very imprecisely estimated, and which has an (absurd) estimated supply elasticity of 1.8, these elasticities lie in a sensible range, ranging from 0.03 for rice to 0.16 for copper. According to the last, for example, the rate of growth of supply will be 0.16 percentage points higher (from say, $2 \%$ a year to $2.16 \%$ a year) for every percentage point that the copper price exceeds its long-run equilibrium. Only for cocoa and coffee do these estimates approach statistical significance.

The final panel shows an important difference between the supply functions for the foods (cocoa, coffee, rice, and sugar) and those for minerals (copper and tin). For the foods, the estimated coefficients on the lagged production growth terms are negative, and in most cases significantly so, while for the minerals, the coefficients are insignificantly positive. Such findings are consistent with the view that, for agricultural 
crops, the most important shocks are weather shocks, which are transitory, while for minerals, permanent shocks are likely to be dominant. If we look back to Eq. (3), such a pattern would induce what we see here, which is negative serial correlation in growth rates for agricultural crops, because the changes in the weather from one year to another is itself serially correlated, with little or no serial correlation for minerals, where the shocks are permanent, with no supposition of negative autocorrelation in the differences.

\section{Summary and conclusions}

We have proposed a statistical model of commodity prices based on Sir Arthur Lewis' account in which the price of tropical produce is held down by the existence of unlimited supplies of labor in tropical countries. In our version of the model, prices are stationary around a long-run trend, production is cointegrated with world income, and the rate of growth of supply responds to deviations of price from its long-run equilibrium. We have fitted this model to long-run data for six commodities, cocoa, coffee, copper, rice, sugar, and tin, over (some subset) of the years 1900-1987.

Our final assessment of the model is mixed. The results of Tables 4 and 5 can certainly be interpreted in a Lewis framework. The deviation of long-run demand from long-run supply exerts upward pressure on both price and production and, except for one commodity (tin), the rate of growth of supply responds positively to deviations of price from its long-run value. However, only for coffee and cocoa are these long-run supply effects significantly different from zero. In spite of the enormous growth of world income in the 20th century, the associated increase in supply has been forthcoming without an increase in the real price of these commodities. As Lewis predicted, increases in the real commodity prices must wait for the elimination of poverty in the tropics.

However, it should also be noted that we have not succeeded in providing any crucial evidence or piece of evidence that would convert a skeptic to the Lewis story. The lack of long-run trend in commodity prices is a remarkable fact that is consistent with the Lewis' account, but as far as our model is concerned, we used the insight in constructing the model, so that its success cannot be counted as any additional support for our formulation. One source of difficulty is that the reversion of prices to their long-run base is very slow, so that even a century of data is not enough to give clear results on either the stationarity of prices or the cointegration of production and output, and the empirical evidence is never very clear in rejecting alternatives. We saw in Section 3 that the mechanical application of standard unit root tests would lead to the conclusion that prices are integrated processes, something that can easily be interpreted in terms of the low power of such tests, especially against slow mean reversion. Nevertheless, we are left without any direct statistical support for the model from the time-series tests.

The more detailed results in Tables 3 and 4, while consistent with the Lewis model, suffer from lack of statistical significance, and the fits of the models come mostly from the univariate time-series representations that are of little interest in the current context. 
The exceptions are cocoa and coffee, the two commodities whose production is confined to the tropics, and for which the Lewis model is most obviously consistent with the data. For all the commodities, the price equations fit well, but only because we are working in levels and regressing price on its own lag. As in our work on speculative storage, our "explanation" of the autocorrelation of prices is essentially an assumed autoregressive process. The production and world income equations are essentially autoregressions in first-differences, and the terms of interest play a relatively minor role. We have spent a great deal of time trying to dissect these results further, to find a crucial piece of evidence that would either support the model, by being hard to interpret without it, or else would refute it. However, as is often the case with economic time-series, it is hard to find clear cut evidence that would convince a true skeptic.

\section{Acknowledgements}

We are grateful to Mark Watson for helpful discussions during the preparation of this paper and to Seth Carpenter for assistance in gathering data. We have benefited from helpful referee reports and from comments by an editor.

\section{Appendix A. Data and sources}

We use three types of data, on world income, on prices, and on production. World income data come from Maddison (1989). Maddison's book has annual series on GDP for 16 (current OECD) countries from 1900 to 1987. To make them comparable, he uses purchasing power parity conversion figures from the OECD and Eurostat for the OECD countries to yield "international dollars" used for conversion of domestic levels. The series have been converted to indices which are then linked to the 1980 benchmark international dollar figure to create an internationally comparable series for each country which can then be summed over countries. The series shown in the table is in billions of 1980 constant dollars. Price data come from the World Bank, and were first used in the study by Grilli and Yang (1988). They are shown as index numbers, as is the US consumer price index. The production data come from a wide range of sources, which are briefly summarized here. Recent annual data on crops (here cocoa, coffee, rice, and sugar) can be readily obtained from the FAO website, http:// www.fao.org. Cocoa production comes from various issues of Gill and Duffus' serial Cocoa Statistics: the units in the table are thousands of metric tons. Coffee data come from the Brazil's Departamento Nacional do Cafe's Annual Statistics: the units are thousands of $60 \mathrm{~kg}$ bags. Data on copper production are taken from the serial Metallstatistik: units are thousands of metric tons. Rice production comes from the FAO, with historical data from FAO (1965); units are millions of quintals. Historical data on sugar are available in FAO (1961); units are hundreds of millions of quintals. Tin production comes from various yearbooks of the International Tin Council; units are metric tons. 


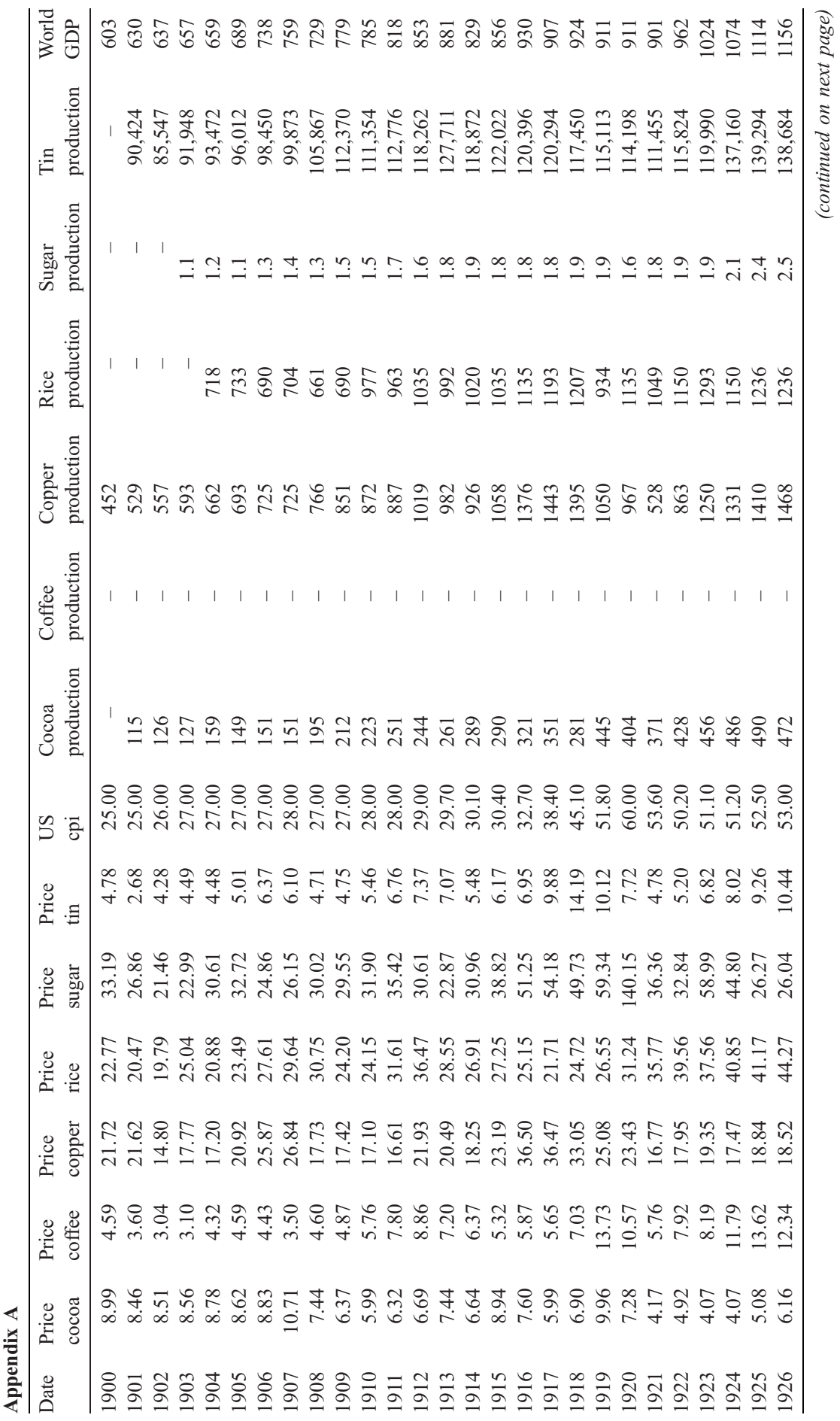




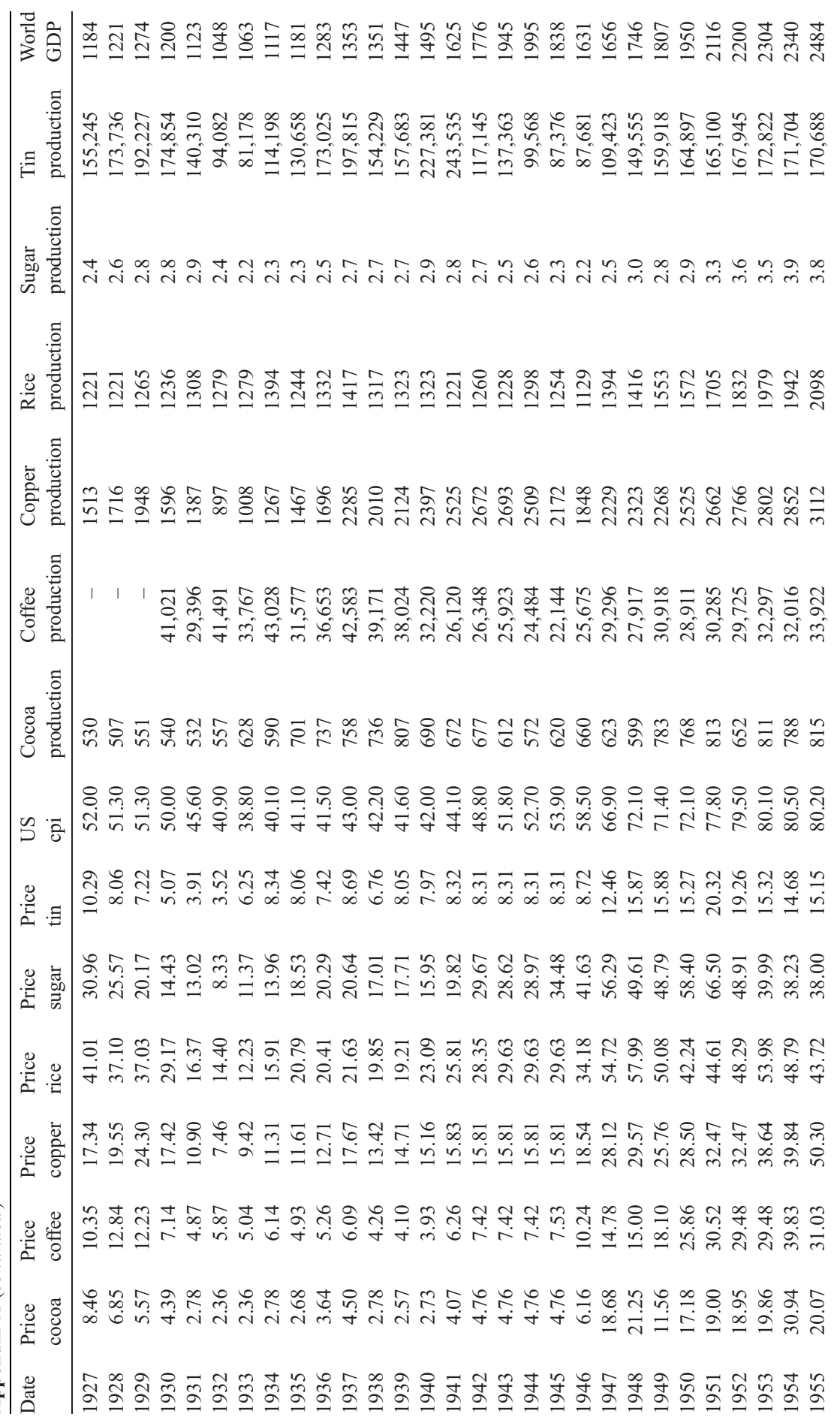




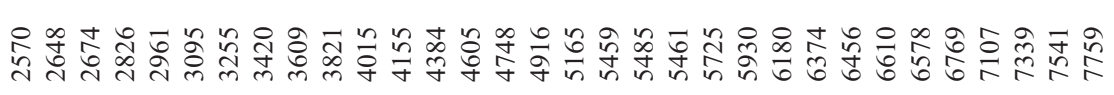

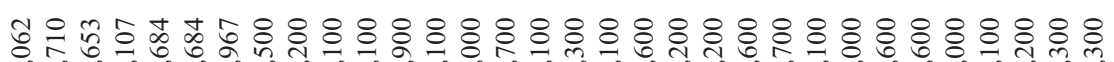

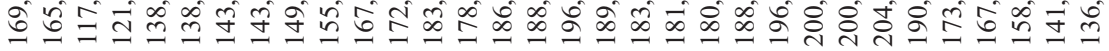

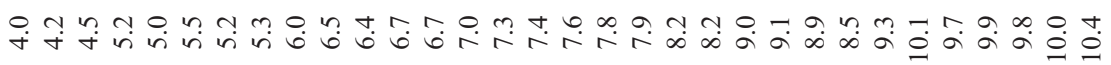

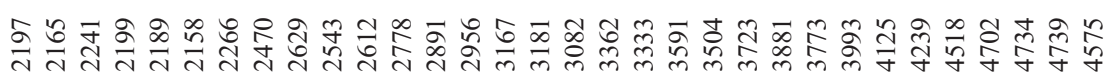

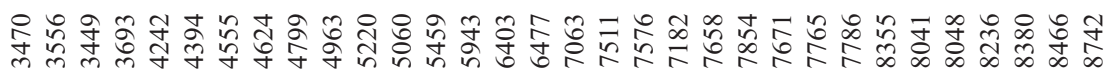

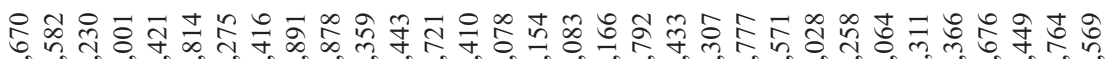

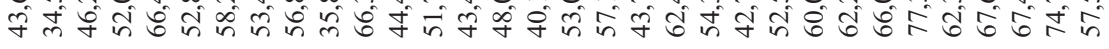

合

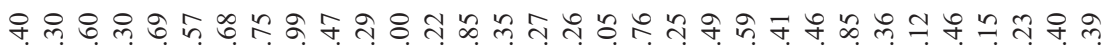

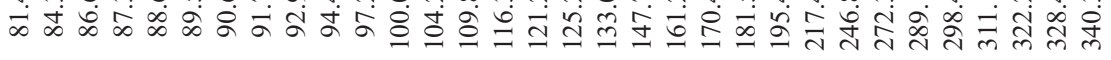

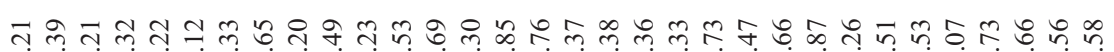

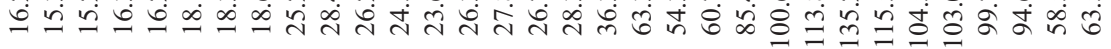

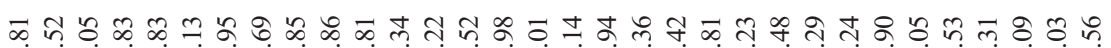

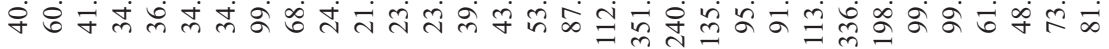

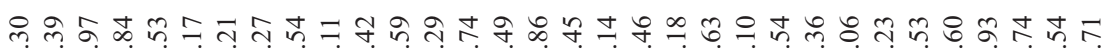

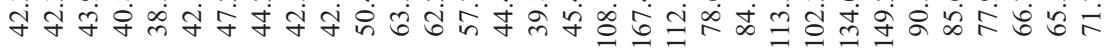

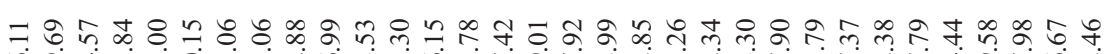

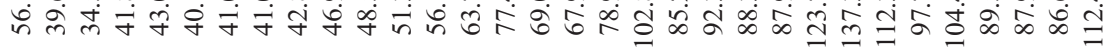

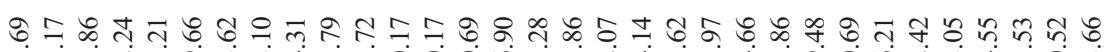
लिखें

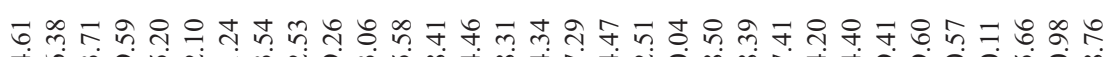

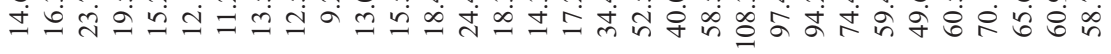

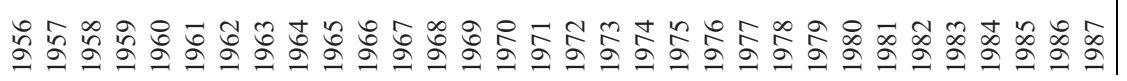




\section{References}

Ahn, S.K., Reinsel, G.C., 1990. Estimation of partially non-stationary autoregressive models. Journal of the American Statistical Association 85, 813-823.

Brazil, Departamento Nacional do Cafe. Anuario Estatistico, various years.

Deaton, A., Laroque, G., 1992. On the behavior of commodity prices. Review of Economic Studies 59, 1-24.

Deaton, A., Laroque, G., 1996. Competitive storage and commodity price dynamics. Journal of Political Economy $104,896-923$.

Engle, R.F., Granger, C.W.J., 1987. Co-Integration and error correction: representation, testing, and estimation. Econometrica 55, 251-276.

Food and Agricultural Organization, 1961. The World Sugar Economy in Figures. Commodities Division, Rome

Food and Agricultural Organization, 1965. The World Rice Economy in Figures. Commodities Division, Rome.

Gill and Duffus. Cocoa statistics. London, various years.

Gray, L.C., 1914. Rent under the assumptions of exhaustibility. Quarterly Journal of Economics 28, 466-489.

Grilli, E., Yang, M.C., 1988. Primary commodity prices, manufactured goods prices, and the terms of trade in developing countries. World Bank Economic Review 2, 1-47.

Halvorsen, R., Smith, T.R., 1991. A test of the theory of exhaustible resources. Quarterly Journal of Economics $106,123-140$.

Hamilton, J.D., 1994. Time-Series Analysis. Princeton Univ. Press, Princeton.

Hotelling, H., 1931. The economics of exhaustible resources. Journal of Political Economy 39, 137-175.

International Tin Council. Tin Statistics. London, annual.

Lewis, A., 1954. Economic development with unlimited supplies of labor. Manchester School 22, 139-191.

Maddison, A., 1989. The World Economy in the 20th Century. OECD, Paris.

Metallstatistik: Metallgesellschaft Aktiengesellschaft: Frankfurt am Main. Die Gesellschaft.

Prebisch, R., 1959. International trade and payments in an era of coexistence: commercial policy in the underdeveloped countries. American Economic Review (Papers and Proceedings) 49, 251-273.

Singer, H.W., 1950. US Foreign investment in underdeveloped areas: the distribution of gains between investing and borrowing countries. American Economic Review (Papers and Proceedings) 40, 473-485.

Watson, M.W., 1994. Vector autoregressions and cointegration. Chapter 47. In: Engle, R.F., McFadden, D.L. (Eds.), Handbook of Econometrics, vol. 4. North-Holland, Amsterdam, pp. 2843-2915. 